\title{
Functional parathyroid cyst in a patient with systemic lupus erythematosus: a case report
}

\author{
Jingjing Jiang ${ }^{1}$, Mei Zhang, Ronghua He, Meiping Shen ${ }^{2}$ and Wei Liu ${ }^{3}$ \\ Department of Endocrinology, The First Affiliated Hospital of Nanjing Medical University, 300 Guangzhou Road, \\ Nanjing 210029, People's Republic of China \\ 'Department of Endocrinology and Metabolism, Zhongshan Hospital, Fudan University, Shanghai 200032, People's \\ Republic of China \\ Departments of ${ }^{2}$ General Surgery ${ }^{3}$ Nuclear Medicine, The First Affiliated Hospital of Nanjing Medical University, \\ Nanjing 210029, People's Republic of China
}

Correspondence

should be addressed

to M Zhang

Email

zhangmei@njmu.edu.cn

\section{Summary}

Functional parathyroid cysts are a rare cause of primary hyperparathyroidism and are often mistaken for thyroid cysts. Systemic lupus erythematosus (SLE) is also a very rare cause of hypercalcemia. We report the case of a 62-year-old woman, who was diagnosed with SLE 30 years ago, presenting with clinical and biochemical features of primary hyperparathyroidism. Laboratory investigation revealed increased serum calcium and parathyroid hormone (PTH) levels; neck ultrasonography (USG) revealed $40 \times 34 \times 26 \mathrm{~mm}$ cystic mass in the left lobe of thyroid gland. PTH level in the cysts was $>2500 \mathrm{pg} / \mathrm{ml}$, determined by USG-guided fine-needle aspiration (FNA). In this case, no evidence for potential pathogenic association between parathyroid cyst and SLE was uncovered. However, the recognition of this association is very important because the therapeutical strategy is completely different. Operative management is usually straightforward and alleviates symptoms and any biochemical abnormalities caused by the cyst.

\section{Learning points:}

- Functional parathyroid cysts are the rare cause of primary hyperparathyroidism and are often mistaken for thyroid cysts.

- SLE is also a very rare cause of hypercalcemia.

- Ultrasound-guided FNA of cystic fluid with assay for PTH level is an accurate method of differentiating parathyroid cyst from thyroid cyst.

- Appropriate management of functional parathyroid cysts is surgical excision.

\section{Background}

Hypercalcemia is a disorder that most commonly results from malignancy or primary hyperparathyroidism. Functional parathyroid cysts are a rare cause of primary hyperparathyroidism (1) and are often mistaken for thyroid cysts (2). Parathyroid cysts have been clinically divided as either functional or nonfunctional (3) (4) (5), depending on their association with hyperparathyroidism.

Systemic lupus erythematosus (SLE) is a multi-system disorder with variable presentation. SLE is also a very rare cause of hypercalcemia. Up to now, about 300 cases of parathyroid cysts and ten cases of SLE patients presenting with hypercalcemia had been reported respectively in the literature. We reported a case of functional parathyroid cyst in a patient with previously diagnosed SLE.

\section{Case presentation}

A 62-year-old woman was admitted to our hospital with a palpable mass in her left anterior neck, which was 


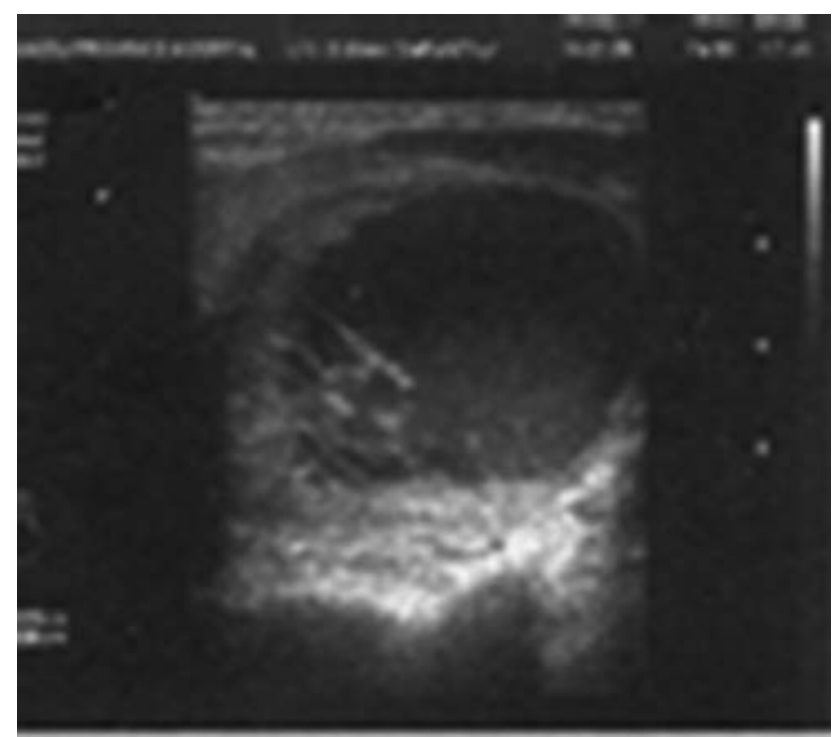

Figure 1

A sagittal ultrasound view demonstrated a $4.03 \mathrm{~cm}$ predominant cyst behind the left lobe of the thyroid gland.

accidentally discovered 1 month ago. She had a 30-year history of SLE and was irregularly treated by prednisolone and Tripterygium wilfordii. She had a 10-year history of hypertension, which was well controlled by nitrendipine. Splenectomy was performed 10 years ago because of hypersplenism. On physical examination, a $4 \times 3 \mathrm{~cm}$ mass was palpable in the left anterior neck, elastic and smooth was identified. She had erythema on her face and both hands. Velcro rales were heard at both lower lobes of the lungs. There was slight edema on both legs.

\section{Investigation}

Initial laboratory tests disclosed the following values: serum calcium $3.55 \mathrm{mmol} / 1$ (normal, 2.15-2.65), phosphorous $1.04 \mathrm{mmol} / \mathrm{l}$ (normal, 0.86-1.86). Hemoglobin was $9.9 \mathrm{~g} / \mathrm{dl}$ (normal, 11.0-16.0) while leukocytes and platelets were normal. 24-h urine calcium was $14.9 \mathrm{mmol}$ (normal, 2.5-7.5). PTH (1-84) was $576 \mathrm{pg} / \mathrm{ml}$ (normal, 10-69), and osteocalcin $63.8 \mu \mathrm{g} / 1$ (normal, 11-43). Thyroid-stimulating hormone was $1.9 \mathrm{mIU} / 1$ (normal, 0.3-4.2), free thyroxine was $13.6 \mathrm{pmol} / 1$ (normal, 12.0-22), free triiodothyronine was $3.7 \mathrm{pmol} / \mathrm{l}$ (normal, 3.1-6.8). Calcitonin was $46.5 \mathrm{pg} / \mathrm{ml}$ (normal, 0-100) as well as tumor markers (AFP, CEA, CA50, CA19-9, CA72-4, CY21-1, NSE) were all normal. Antinuclear antibody level was $358 \mathrm{U} / \mathrm{ml}$ (normal, 0-40) and anti-dsDNA level was $39 \mathrm{U} / \mathrm{ml}$ (normal, 0-100). Anti-Sm antibody was also positive. C3 was $0.39 \mathrm{~g} / \mathrm{l}$ (normal, 0.88-2.01) and C4
$0.05 \mathrm{~g} / \mathrm{l}$ (normal, 0.16-0.47). Erythrocyte sedimentation rate (ESR) was normal and rheumatoid factor (RF) was negative. Hyaluronic acid was $360 \mathrm{ng} / \mathrm{ml}$ (normal, 2-110), type IV collagen $154.2 \mathrm{ng} / \mathrm{ml}$ (normal, 19.8-112.8), and type III precollagen $213.6 \mathrm{ng} / \mathrm{ml}$ (normal, 0-120), suggesting hepatic fibrosis.

$\mathrm{X}$-ray showed subperiosteal bone resorption in the middle and distal phalanges of the fingers. But no sign of osteoporosis was observed in skull, neck of femur, or lumbar spine. Spot-like shadows were seen at both lower lobes of the lungs on X-ray. Ultrasonography (USG) scan revealed a $40 \times 34 \times 26 \mathrm{~mm}$ cystic mass in the left lobe of thyroid gland (Fig. 1). High-intensity images on both $\mathrm{T} 1$ and T2-weighted magnetic resonance imaging (MRI) suggested that the cystic area was composed of liquid (Fig. 2). And USG scan of kidney and urinary tract revealed nephrolithiasis in the left kidney. Parathyroid scintigraphy using ${ }^{99 \mathrm{~m}}$ Tc-MIBI showed intense accumulation and persistent uptake of radioactivities by the wall of the cyst (Fig. 3). Fine-needle aspiration (FNA) of the cyst was performed under ultrasound guidance, and $20 \mathrm{ml}$ of bloody fluid was removed. The aspirate's PTH level was $>2500 \mathrm{pg} / \mathrm{ml}$. The mass shrinked immediately after aspiration, but reemerged overnight. Cytological analysis revealed a few macrophages and benign-appearing, follicular cells.
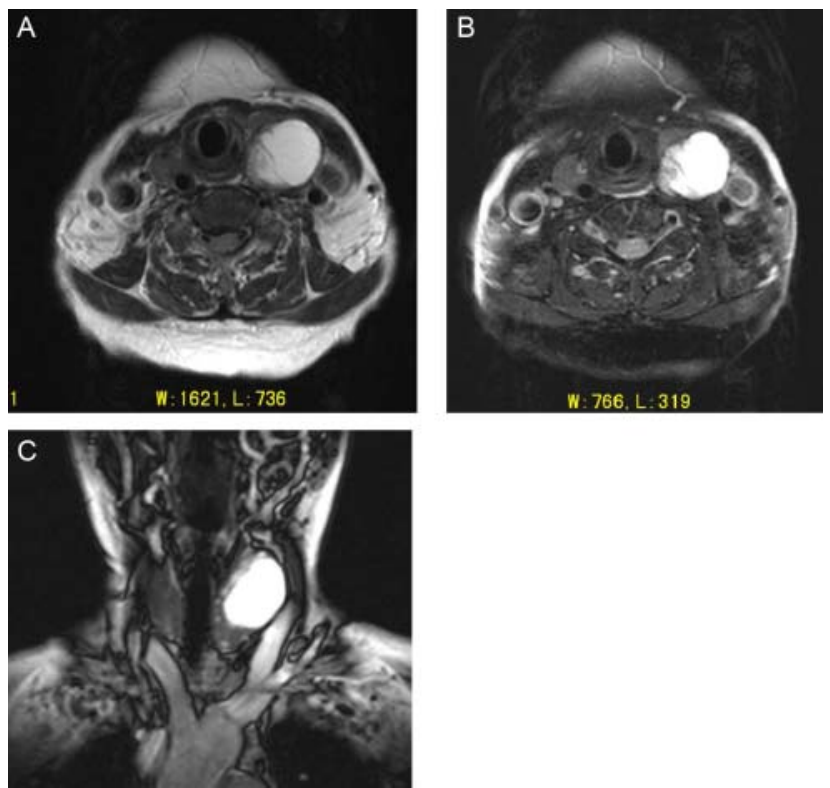

Figure 2

The cyst is located at the lower part of anterior neck behind the left lobe of the thyroid gland. High-intensity imaging of the content on both T1- (A) and T2- (B and C) weighted MRI suggested that the cyst area was filled with fluid. 

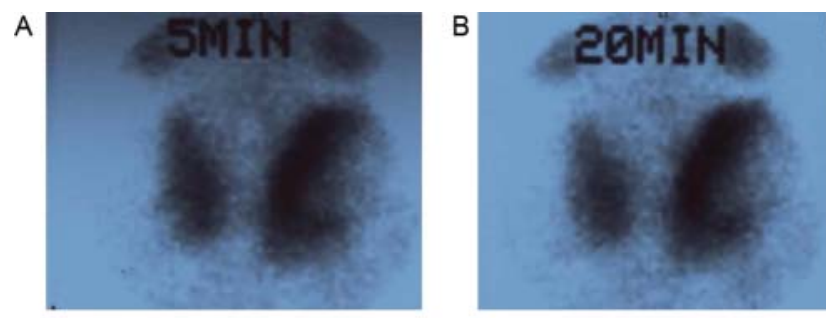

C
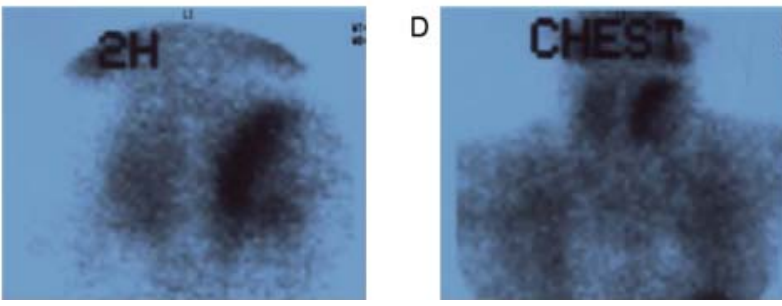

Figure 3

${ }^{99 m}$ TC-MIBI scintigraphy demonstrated focal accumulation and persistent uptake of radiotracers at the wall of the cystic mass. (A and B) Early images of 99mTc-MI; Panels C and D: delayed images of 99mTc-MIBI.

\section{Treatment}

Serum calcium persisted around $3 \mathrm{mmol} / \mathrm{l}$ despite treatment with oral alendronate $(70 \mathrm{mg}$, qw) and calcitonin shot (200 IU, qd). Neck exploration was subsequently performed and $40 \times 30 \mathrm{~mm}$ parathyroid cyst was surgically removed. Neither vascular invasion nor metastasis to local lymphnodes was observed. On the histology, parenchymal cells were arranged in trabecular pattern without cellular atypia or capsular invasion. The tissue contained abundant degenerative collagen fibers and blood vessels (Fig. 4). Histological examination verified a cystic adenoma of parathyroid gland.

After surgery, the patient complained of numbness of hands, which was relieved after taking calcium gluconate tablets $(0.5 \mathrm{~g}$, tid). Three days after surgery the patient left hospital, with serum PTH level being $19.9 \mathrm{pg} / \mathrm{ml}$ and serum calcium level being $2.29 \mathrm{mmol} / \mathrm{l}$ under oral substitution of calcium. SLE was treated with prednisolone. Thalidomide $(50 \mathrm{mg}, \mathrm{qn})$ was added to treat erythema, which subsided 1 month later. The patient is currently in good condition without any medication, but still suffered from SLE.

\section{Discussion}

Hypercalcemia is a common electrolyte abnormality. More than $90 \%$ of cases of hypercalcemia are due to primary hyperparathyroidism or malignancy.

Macroscopic parathyroid cysts are rare clinical lesions, with $<300$ cases reported in the literature. These cysts are usually classified as either functional or nonfunctional based on serum PTH and calcium levels. Approximately one-third of parathyroid cysts are functional (3) (4) (5) and account for $1 \%$ of all cases of hyperparathyroidism (5). These cysts are more common in females than males (2.5:1) and usually located in an inferior gland with a leftsided predominance as in this case.

Parathyroid cysts account for $<1 \%$ of neck masses and often present as a solitary nodule in the neck, posing a diagnostic challenge. USG, MRI, as well as scintigraphy, can provide helpful but limited information. Preoperative cyst fluid analysis is of great value for differential diagnosis (6) (7). The fluid from a parathyroid cyst is usually clear and colorless, containing elevated PTH level, though bloody fluid has also been reported (5) (8). Ultrasoundguided FNA of cystic fluid with assay for PTH level is an accurate method of differentiating parathyroid cyst from thyroid cyst. In the present case, the content was bloody with extremely high levels of PTH, confirming the diagnosis of a functional parathyroid cyst. High level of tumor antigen-like CA19-9 in cyst content has been previously reported (8). However, analysis of the cyst fluid revealed no elevation of either CA19-9 or other tumor markers in this case.

SLE is a very rare cause of hypercalcemia, with only ten cases reported (9) (10). The pathogenesis involves the presence of stimulatory anti-PTH receptor autoantibodies or excessive endogenous production of PTHrP primarily due to lymphadenopathy (10) (11). Interestingly, SLE was

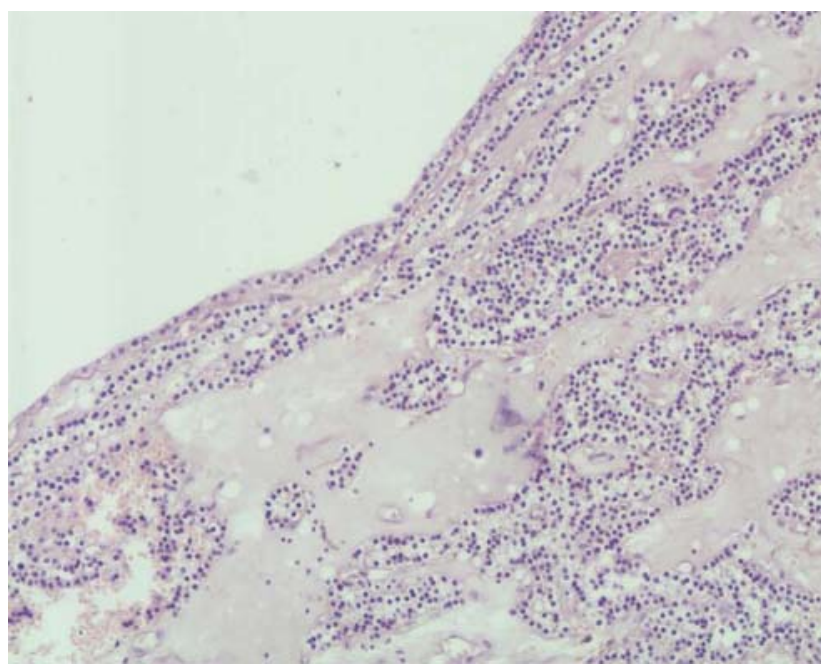

Figure 4

Parenchymal cells were arranged in trabecular pattern. The tissue contained abundant degenerative collagen fibers and blood vessels. There was no cellular atypia or capsular invasion $(H \& E$, original magnification $\times 100)$. 
also found to coexist with hypoparathyroidism, with four cases reported in literature (12). The underlying pathophysiology was supposed to be either a common genetic predisposition or the extension of the autoimmune process to the parathyroid glands, which is still under debate (12).

In this presented case, SLE was stable and could be safely ruled out as a major cause of hypercalcemia because PTH level was very high and serum calcium;eve; normalized soon after surgery. Two cases have been previously reported of primary hyperparathyroidism and SLE in a single patient (13) (14). Together with this case, all three patients were women aged over 40 years with previously diagnosed SLE. They were all treated with corticosteroids and the conditions of SLE were relatively stable with anti-dsDNA normal in two patients. Postoperatively, all patients were relieved of hypercalcemia.

The pathogenesis of parathyroid cysts varies from degeneration of a parathyroid adenoma (infarction within the adenoma), coalescence of microcyst with hypersecretion within the capsule of the gland, or persistent embryological remnants of branchial cleft cysts (15). No involvement of autoimmunity in hyperparathyroidism has been suggested in literature. Considering the relative frequency of these two diseases in a general population, especially in middle-aged women, this coexistence cannot be ruled out as a coincidence.

In this case, no evidence for potential pathogenic association between parathyroid cyst and SLE was uncovered. However, the recognition of this association is still important because the therapeutic strategy is completely different.

\section{Declaration of interest}

The authors declare that there is no conflict of interest that could be perceived as prejudicing the impartiality of the research reported.

\section{Funding}

This research did not receive any specific grant from any funding agency in the public, commercial or not-for-profit sector.

\section{Patient consent}

Written informed consent was obtained from the patient for publication of this case report.
Author contribution statement

All co-authors listed contributed substantially to the preparation of this manuscript.

\section{References}

1 Gough IR 1999 Parathyroid cysts. Australian and New Zealand Journal of Surgery 69 404-406. (doi:10.1046/j.1440-1622.1999.01587.x)

2 Jha BC, Nagarkar NM, Kochhar S, Mohan H \& Dass A 1999 Parathyroid cyst: a rare cause of an anterior neck mass. Journal of Laryngology and Otology 113 73-75. (doi:10.1017/S0022215100143208)

3 Clark OH 1978 Parathyroid cysts. American Journal of Surgery 35 395-402. (doi:10.1016/0002-9610(78)90073-9)

4 Rosenberg J, Orlando R, III, Ludwig M \& Pyrtek LJ 1982 Parathyroid cysts. American Journal of Surgery 143 473-480. (doi:10.1016/00029610(82)90198-2)

5 Ujiki MB, Nayar R, Sturgeon C \& Angelos P 2007 Parathyroid cyst: often mistaken for a thyroid cyst. World Journal of Surgery 31 60-64. (doi:10.1007/s00268-005-0748-8)

6 Silverman JF, Khazanie PG, Norris HT \& Fore WW 1986 Parathyroid hormone (PTH) assay of parathyroid cysts examined by fineneedle aspiration biopsy. American Journal of Clinical Pathology 86 776-780.

7 Kodama T, Obara T, Fujimoto Y, Ito Y, Yashiro T \& Hirayama A 1987 Eleven cases of nonfunctioning parathyroid cyst - significance of needle aspiration in diagnosis and management. Endocrinologia Japonica 34 769-777. (doi:10.1507/endocrj1954.34.769)

8 Makino T, Sugimoto T, Kaji H, Yamaguchi T, Kitazawa R, Yamauchi M, Sowa H, Chen Q, Nomura R, Tsukamoto T et al 2003 Functional giant parathyroid cyst with high concentration of CA19-9 in cystic fluid. Endocrine Journal 50 215-219. (doi:10.1507/endocrj.50.215)

9 Erdozain JG, Egurbide MV, Ruiz-Irastorza G, Ojanguren J \& Aguirre C 2004 Systemic lupus erythematosus presenting as acute symptomatic hypercalcemia. Lupus 13 132-134. (doi:10.1191/ 0961203304lu476cr)

10 Farah R, Farah R \& Makhoul N 2006 Severe hypercalcemia as a presenting sign of systemic lupus erythematosus. European Journal of Internal Medicine 17 206-208. (doi:10.1016/j.ejim.2005.09.025)

11 Deftos LJ, Burton DW, Baird SM \& Terkeltaub RA 1996 Hypercalcemia and systemic lupus erythematosus. Arthritis and Rheumatism 39 2066-2069. (doi:10.1002/art.1780391217)

12 Attout H, Guez S, Durand J, Dubois F, Rughoobur A \& Sériès C 2007 Hypoparathyroidism in systemic lupus erythematosus. Joint, Bone, Spine 74 282-284. (doi:10.1016/j.jbspin.2006.06.008)

13 Galrao LD, Lima IV, Santos L \& Santiago MB 2004 Primary hyperparathyroidism in a patient with systemic lupus erythematosus. Arquivos Brasileiros de Endocrinologia e Metabologia 48 555-558. (doi:10.1590/S0004-27302004000400017)

14 Benekli M, Savas MC, Erdem Y, Yalcin AU, Yasavul U, Turgan C \& Caglar S 1998 Primary hyperparathyroidism in a patient with systemic lupus erythematosus-antiphospholipid syndrome. Nephron 79 215-216. (doi:10.1159/000045027)

15 Ippolito G, Palazzo FF, Sebag F, Sierra M, De Micco C \& Henry JF 2006 A single-institution 25-year review of true parathyroid cysts. Langenbeck's Archives of Surgery 391 13-18. (doi:10.1007/s00423-005-0579-y)

Received in final form 24 December 2014

Accepted 14 January 2015 